\title{
Regeneration niche of the Canarian juniper: the role of adults, shrubs and environmental conditions
}

\author{
Rüdiger OtTo $^{1 *}$, Bertil O. KRÜsI ${ }^{2}$, Juan D. Delgado ${ }^{3}$, José María FERnÁndeZ-PALAcios ${ }^{1}$, \\ Eduardo GARcíA-DEL-REY ${ }^{1}$, José Ramón ARÉVALO ${ }^{1}$ \\ ${ }^{1}$ Departamento de Ecología, Facultad de Biología, Universidad de La Laguna, 38206 La Laguna,Tenerife, Canary Islands, Spain \\ ${ }^{2}$ Zürich University of Applied Sciences ZHAW, School for Life Sciences and Facility Management, Grüiental, 8820 Wädenswil, Switzerland \\ ${ }^{3}$ Área de Ecología, Departamento de Sistemas Físicos, Químicos y Naturales, Universidad Pablo de Olavide, Ctra. de Utrera, km 1, \\ 41013 Seville, Spain
}

(Received 25 September 2009; revised version 26 January 2010; accepted 4 February 2010)

\author{
Keywords: \\ Juniperus turbinata ssp. canariensis / \\ regeneration / \\ microhabitat / \\ GLM / \\ Canary Islands
}

\begin{abstract}
- Canarian Juniper woodlands, now very scarce, are rich in endemic and endangered plants. However, many aspects of juniper regeneration are almost unknown.

- This paper relates occurrence and abundance of recruits of Juniperus turbinata ssp. canariensis to (1) small-scale soil characteristics; (2) vegetation cover; and (3) distance to conspecific adults in two contrasting juniper stands in the eastern mountains of Tenerife. We used non-parametric classification trees and generalised linear models (GLM) to evaluate the effect and importance of each explanatory variable on the occurrence of juniper saplings.

- Sapling density, vitality and growth rate, as well as fruit production by adult trees, but neither cone density on the ground nor sapling size, varied significantly with respect to slope orientation, representing environmental stress. Within each stand, distance to nearest adult tree was the most important variable explaining the spatial distribution of juniper saplings and availability of seeds in cones. Additionally, saplings were positively associated with shrub cover at the microsite-level, but not with spiny shrub cover. Soil depth and rock cover had a weak negative effect on sapling establishment, but only at the south-facing site and in the open space microhabitat.

- Results suggest that recruitment of Canarian juniper is facilitated by microhabitats offered by adults and shrubs. The key factors affecting recruitment are thought to be (1) favourable microenvironmental conditions and (2) high ambient seed availability. Browsing intensity in recent decades was very low. The presence of spiny shrubs did not favour juniper establishment. Facilitation therefore appears to result from amelioration of abiotic conditions rather than from protection against herbivory.
\end{abstract}

\section{INTRODUCTION}

Seed dispersal and seedling establishment represent a major bottleneck in woody plant population dynamics (García, 2001; Rey and Alcántara, 2000), especially in arid and semiarid environments (Chambers, 2001; Gómez-Aparicio et al., 2005; Weltzin and McPherson, 1999). Study of spatial distributions of recruits in relation to seed sources and to abiotic and biotic factors has been a productive field of research in Mediterranean ecosystems over the past decade (Kollmann, 2000; Montesinos et al., 2007). Physical and biological factors that influence recruitment are usually highly heterogeneous in space. These factors vary at different scales (García and Houle, 2005; Gómez-Aparicio, 2008; Maltez-Mouro et al., 2007).

At a regional or landscape scale, habitat-specific environmental filters have been reported to affect regeneration

\footnotetext{
*Corresponding author: rudiotto@ull.es
}

patterns. Slope orientation is an important factor for recruitment in juniper woodlands (Johnson and Miller, 2006) and for Mediterranean forest restoration (Gómez-Aparicio et al., 2004). Substrate characteristics and soil development influence establishment of Mediterranean tree species (Gómez-Aparicio, 2008).

Variation in microclimate and light conditions can generate local within-habitat spatial heterogeneity. These conditions characterise specific microhabitats, often offered by trees or shrubs (nurse plant effects), that facilitate seedling emergence and establishment (Matthes and Douglas, 2006; Smit et al., 2009). Furthermore, facilitation of tree regeneration through microhabitats offered by nurse plants can also indicate protection from herbivory (Gómez Aparicio et al., 2008). In fact, the role of herbivory shaping juniper stands has only recently been reported (Olano et al., 2008; Rozas et al., 2008).

At an even finer spatial scale $(<1 \mathrm{~m})$, topsoil properties and micro-topography determine soil moisture and nutrient 
availability for plants (Lechowicz and Bell, 1991). These features influence recruitment (García and Houle, 2005; Herrera, 2002). Moreover, litter cover (Facelli et al., 1999; MaltezMouro et al., 2007) and nurse structures such as tree stumps can be associated with seedling emergence and survival (Smit et al., 2005).

Juniperus turbinata ssp. canariensis is a vertebratedispersed fleshy-fruited tree, endemic to the Canarian and Madeiran archipelagos. Its actual populations on most of the Canary Islands represent only small remnants of an ecosystem, the thermophilous woodlands, much more extensive in the past (Fernández-Palacios et al., 2008). We lack information about seed dispersal, seedling establishment and sapling distribution for the Canarian juniper. Microhabitat, seed dispersal and abiotic stress influence recruitment of Juniperus species in semi-arid regions (García, 2001; Milios et al., 2007; Montesinos et al., 2007; Van Auken et al., 2004). Conspecific adult trees are important as nurse plants and as seed sources. Distance to conspecific adults is a major influence on spatial patterns of Mediterranean oak recruits (Maltez-Mouro et al., 2007; 2009). Furthermore, recent studies on Juniperus thurifera suggest that intense browsing pressure during long periods can strongly influence recruitment processes and the spatial structure of juniper stands (Olano et al., 2008; Rozas et al., 2008). We hypothesise that these factors could also influence recruitment of Canarian juniper.

In this paper, we analyse the distribution of juniper recruits (seeds in cones on the ground, reflecting overall seed availability, and saplings) at different spatial scales: (i) in relation to small-scale soil and vegetation characteristics (distance $<2 \mathrm{~m}$ ); (ii) with respect to the distance to the nearest conspecific adult tree (up to $15 \mathrm{~m}$ ); and (iii) comparing two juniper stands with different orientation $(>1 \mathrm{~km})$, one situated on a north-facing slope and one on a south-facing slope. Our main questions were: (1) are juniper saplings spatially associated with specific small-scale soil and vegetation characteristics? (2) How do distance to conspecific adult trees and seed availability influence juniper sapling presence? (3) Are observed patterns consistent across two ecologically contrasting sites? What is the effect of slope orientation, reflecting environmental stress? (4) What is the approximate age of the saplings?

\section{MATERIALS AND METHODS}

\subsection{Canarian juniper woodlands}

Juniperus turbinata Guss. ssp. canariensis (Guyot) Rivas-Mart., Wildpret and Pérez is an endemic fleshy-fruited monoecious tree of the Canarian and Madeiran archipelagos, (northeastern Atlantic Ocean, off the African coast). In the Canaries, fruits (cones) containing 3-7 seeds are dispersed principally by endemic lizards (Gallotia galloti Oudart) and, nowadays, to a much lesser extent by frugivorous birds, e.g., the locally endangered raven (Corvus corax L. canariensis. Hartert \& Kleinschmidt), near extinction on Tenerife; blackbird (Turdus merula L. cabrerae Hartert) and the summer visitor turtle dove (Streptopelia turtur L.). Insects, rabbits (Oryctolagus cuniculus
L.) and rats (Rattus rattus L.) feed on cones. These last two vertebrates were introduced after the Castilian Conquest, ca 520 y ago.

The Canarian juniper occurs on all Canarian Islands except the more arid eastern islands, Fuerteventura and Lanzarote (Izquierdo et al., 2004), where human activities probably brought about its extinction. Potentially, juniper would form one type of thermophilous woodland with sclerophyllous shrub and tree species in the semiarid infra- and mesomediterranean bioclimatic belt. The altitude of this belt varies between 200 and $400 \mathrm{~m}$ a.s.l. on humid windward slopes and between 400 and $800 \mathrm{~m}$ a.s.l. on more arid leeward slopes of the islands. Juniper woodlands occupy intermediate altitudes between the arid coastal or succulent scrub and the more humid forest zone of the mountain regions, where laurel and pine forests would naturally dominate. Mean annual precipitation within this intermediate zone varies between 200 and $400 \mathrm{~mm}$. Mean annual temperature is about $17^{\circ} \mathrm{C}$. The climate is semiarid Mediterranean with a pronounced dry period from May to September. Most precipitation occurs in winter. The Canarian juniper is not very demanding with respect to soil conditions; it will able to grow on poorly developed, stony soils, but soils of juniper woodlands can vary substantially according to altitude and to exposure to the dominant northeast trade winds (Fernández-Palacios et al., 2008).

Juniper woodlands on Tenerife have been degraded and destroyed considerably during the past five centuries. The preferred zone for this vegetation type has also been the most attractive for human settlement and for agriculture. Juniper wood has been used for many kinds of tools and for constructing houses (Fernández-Palacios et al., 2008). Tenerife's best conserved and most extensive stand of about 64 ha is located in Afur, in the Anaga Massif in the eastern part of the island, included in the "Parque Rural de Anaga" Protected Area. The Canarian juniper woodlands are included in the list of habitats of interest by the European Community (Habitat 9560, DIRECTIVA 92/43/CEE).

\subsection{Study site}

This study was conducted in the best conserved stands of Juniperus turbinata ssp. canariensis on Tenerife, near the village of Afur in the Anaga Massif (UTM coordinates: $X=378.400 ; Y=3.159 .912$ ). We studied two stands on opposite slopes of the Barranco del Sabinal valley, one exposed to the South, Afur Sur (AS) and the other to the North, Afur Norte (AN). Different local climates clearly differentiate the two sites. The north-facing slope is influenced by humid trade winds and shows lower levels of insolation and air temperature. Altitudinal ranges are very similar and vary from 275 to $400 \mathrm{~m}$ (AS) and from 250 to $375 \mathrm{~m}$ a.s.l. (AN), respectively, with slopes ranging between 30 and $34^{\circ}$. Overall mean annual precipitation recorded at the nearest meteorological station (Anaga-Roque Negro-Porquera, 1988-2004) is $255 \mathrm{~mm}$. Soil parent materials consist of old basaltic lava flows and pyroclastics. Land use for both stands is limited to very extensive goat grazing. Occasionally in the past, these forests have been cut for timber and firewood (Fernández-Palacios et al., 2008).

Monospecific stands of Juniperus turbinata occur at AS. Erica arborea L., a tree species of the more humid laurel forest belt, occurs at AN. This species occupies windward slopes immediately above the thermophilous woodlands, especially at the upper limit of the stand (mean cover 10\%). Stand characteristics and understorey shrub species composition have been described by Otto et al. (2006). Densities of adult juniper tree were 202 and 91 per ha for AS and AN respectively. Basal area reached 12.4 and $4.8 \mathrm{~m}^{2} /$ ha respectively. 


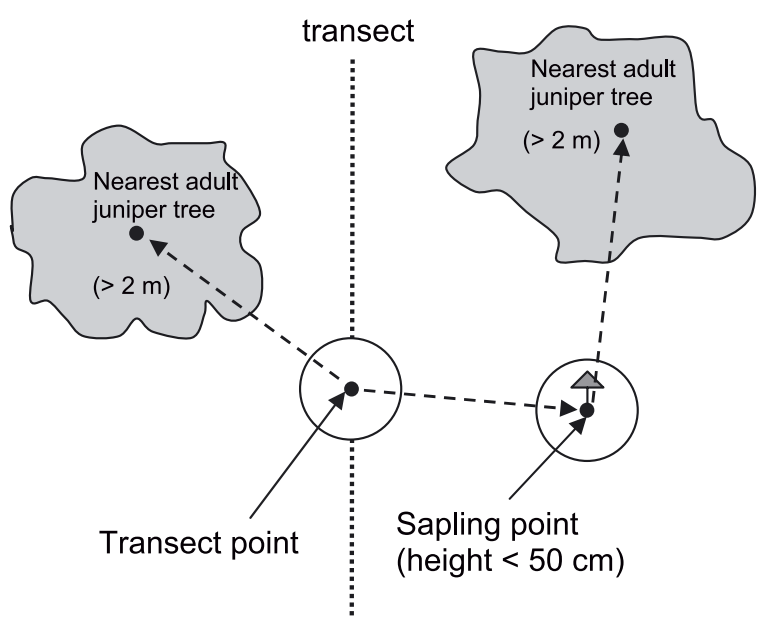

Figure 1. Sampling design. 100 transect points were selected systematically within two juniper habitats. Distance from transect point to nearest sapling and nearest adult juniper tree, as well as distance from sapling point to nearest adult juniper tree were measured.

Association of juniper saplings with thorny shrubs could suggest protection from browsing. To detect such an association if present, we grouped spiny shrub species together: Opuntia dillenii (Ker-Cawl.) Haw., O. maxima Mill., Agave americana L., Carlina salicifolia (L.f.) Cav., Euphorbia canariensis L., and Rubus ulmifolius Schott. Browsing pressure by goats was low in previous decades in that region (Mata et al., 2006). We assumed no major differences in browsing intensity between the two stands studied. That we did not find any browsed juniper saplings during fieldwork further supports the idea of low actual browsing pressure.

\subsection{Sampling design and tree ring measurements}

At each site, 50 transect points (hereafter TP) were placed over an area of approximately 30 ha in a systematic sampling design using a varying number of vertical transects (from valley bottom to crest) $30 \mathrm{~m}$ apart with transect points separated $30 \mathrm{~m}$ apart along the transects. The overall sampling design formed a grid with points $30 \mathrm{~m}$ apart. If the TP was inaccessible or heavily disturbed, it was displaced $5 \mathrm{~m}$ up- or downwards. Following the "closest individual" method (Mueller-Dombois and Ellenberg, 1974; Fig. 1), we measured distances from the TP to the nearest adult juniper tree (nearest adult tree, hereafter, individuals with height $>2 \mathrm{~m}$, following the classification by Montesinos et al., 2007) and to the nearest sapling (nonreproductive plants with height $\leq 50 \mathrm{~cm}$ ). The location of the nearest sapling to each TP was called Sapling Point (SP, hereafter). Additionally, we recorded the distance between SP and the nearest adult tree. Since transect points were selected systematically, they represent the general environmental conditions of each study site. We wanted to compare these specific conditions where saplings are present. Significant differences between TP and SP indicate a spatial filter influencing the regeneration process.

We assumed that a circle with radius of $1 \mathrm{~m}$ represents the area of influence or microsite for saplings up to $50 \mathrm{~cm}$ of height. Within this area, we visually estimated the following microsite characteristics at each TP and SP: rock cover (percentage of rock outcrops and stones $>30 \mathrm{~cm}$ diameter); stone cover (percentage of stones with diameter between 1 and $30 \mathrm{~cm}$ ); uncovered or bare soil (soil and gravel with particle diameter $<1 \mathrm{~cm}$ ); litter cover (all dead organic material proceeding from tree, shrub and herb layer); moss cover; herb cover (annual and perennial species with height $\leq 50 \mathrm{~cm}$ ); shrub cover (total cover of all shrubs with height between 0.5 and $2 \mathrm{~m}$ ), spiny shrub cover (total cover of all spiny shrubs), juniper tree cover and tree cover of Erica arborea (present only at AN). Soil depth was measured at TP and SP using a $4 \mathrm{~mm}$ diameter, $45 \mathrm{~cm}$ length metal stick driven vertically into the soil until it reached bedrock. At each point, four replicate measurements were made $1 \mathrm{~m}$ from the selected point. These four measurements were grouped symmetrically around the selected point.

We counted cone density on the ground at each TP and SP in four $20 \times 20 \mathrm{~cm}$ quadrats located symmetrically around the individual/point at a distance of $1 \mathrm{~m}$. For the nearest adult tree from TP, we recorded fruit production, defined as the number of cones at the crown edge within four $20 \times 20 \mathrm{~cm}$ quadrats located at the end of two crown diameters (one in direction to the valley bottom and one perpendicular to it), canopy closure (estimated visually), vitality of the individual (percentage of green leaves, not considering discoloured or dry leaves), individual height, DBH (diameter at breast height) and crown diameter. We also measured height, crown diameters and vitality of saplings, and counted all saplings within a circle of $5 \mathrm{~m}$ radius around TP in order to calculate sapling density of each site. Field work took place throughout 2005.

About 15 saplings were selected per stand. Saplings growing within the canopy border microhabitat and with an even distribution in height classes up to $1 \mathrm{~m}$ were selected in order to evaluate approximate age of the saplings and to check for differences in growth rate between stands. Stems were cut at ground level. Stem discs were dried and polished with sand paper. Tree rings were counted and measured using a sledge microtome and the TSAP (time series and analysis programme) at the dendro laboratory of the Swiss Federal Institute for Forest, Snow and Landscape research (WSL), Birmensdorf, Switzerland. We did not check for deviations of tree-ring counts with respect to actual age, applying methods of cross-dating of tree ring series, since this deviation, caused by double or absent rings, was found to be rather low $(<3 \%$ ) for Juniperus thurifera (Olano et al., 2008) and we were mainly interested in the estimated age of saplings.

\subsection{Data analysis}

We first compared general site conditions at the two chosen juniper stands. We analysed differences in soil characteristics and cone density at TP as well as characteristics of nearest adults and saplings. We applied the nonparametric Kolmogorov-Smirnov test for two independent groups (Sokal and Rohlf, 1995). We analysed variations in soil characteristics between TP and SP at each site and pooled for the two sites with the nonparametric Wilcoxon test for related sample pairs. To avoid overlapping of circular plots of corresponding TP and SP, we skipped those pairs of points closer than $1.5 \mathrm{~m}$ to each other ( 2 points for AS and 9 points for AN). We retained a total of $89 \mathrm{TP}$ (absence of saplings) and 89 SP (presence of saplings) points to enter in the regression analysis.

Before entering the explanatory variables in the multiple regression models, we constructed a correlation matrix using nonparametric Spearman rank correlation coefficients to explore relationships among explanatory variables. We were especially interested in the relation between distance to nearest adult tree and soil 
characteristics. We then selected a set of explanatory variables for the regression analysis by eliminating those variables that were highly correlated with each other (correlation coefficient $r>0.60$ ) in order to avoid collinearity and eliminate redundant information (in case of GLM). Litter cover and juniper tree cover were highly correlated with distance to nearest adult tree (Spearman rank correlation coefficient $r=0.69$ and 0.68 , respectively). Characteristics of the nearest adult trees were not included as explanatory variables for predicting presence of juniper saplings in regression analyses.

In a second step, we used nonparametric classification trees (Zuur et al., 2007) to evaluate the effect of each explanatory variable on the occurrence of juniper saplings $(\mathrm{TP}=0$, versus $\mathrm{SP}=1)$ as the response variable. Classification and regression tree analysis (CART) is a relatively new technique in ecology (Zuur et al., 2007). The method repeatedly partitions observations into two homogenous groups based on the values (order) of an explanatory variable. These techniques deal better with nonlinearity than does ordinary least squares regression (OLS) and can identify interactions missed by other methods in ecological studies (Zuur et al., 2007). This statistical technique also indicates the relative importance of each explanatory variable. Tree models are not affected by transformations of explanatory variables. The minimum number of observations per node required for a split to be attempted, was set at 20. The full tree was obtained with the default complexity parameter set to 0.001 (see Zuur et al., 2007, for a full explanation).

To compare statistical results, we also applied generalised linear models (GLM; Dobson, 1990), including the same explanatory variables and using best set selection with AIC (Akaike information criterion) for the optimal model, binomial distribution and logistic link function, as recommended for presence/absence data in ecological analysis (Crawley, 1993). Use and comparison of several statistical approaches to the same set of ecological data, as applied here, are recommended. This style of data analysis can yield improved statistical and ecological conclusions (Zuur et al., 2007). Statistical programs Brodgar 2.5.6 (www.brodgar.com) and STATISTICA 8 were used to conduct multivariate analyses.

To evaluate and to visualise the relationship between spatial distribution of saplings and cone density on the ground in relation to distance to nearest adult tree, we calculated percentage of frequencies and average density values, respectively, within 12 distance classes (each meter up to $11 \mathrm{~m}$, plus one class $>11 \mathrm{~m}$ distance to adult tree).

\section{RESULTS}

Analysis of general site conditions as recorded at TP revealed that the south-facing juniper site AS is characterised by shallower soils, higher rock and stone cover as well as much lower moss cover compared to the north-facing one (Tab. I). All other soil characteristics, as well as cone density on the ground, did not differ significantly between the two sites. Height, DBH and crown radius of adult juniper trees were very similar for both stands. However, significant differences between stands were observed for fruit production, canopy closure and vitality of adults. Individuals at the southfacing stand were less productive, less vital, and had less dense canopies. Sapling density, height and vitality were significantly higher at AN compared to AS (Tab. I). Sapling growth was much faster at the north-facing site $(2.94$ and $1.28 \mathrm{~cm} / \mathrm{y}$,

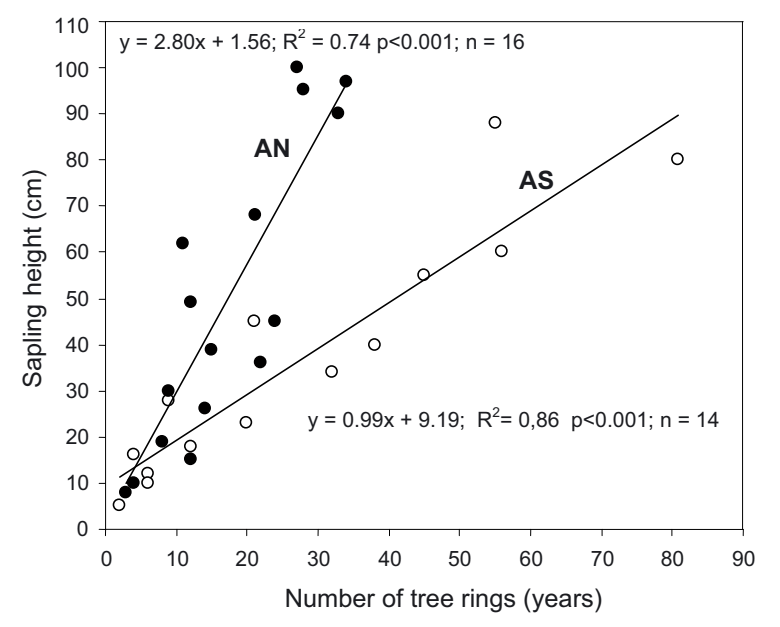

Figure 2. Results of linear regression models with sapling height as depending variable and tree rings counts as independent variable for sites Afur South (AS) and Afur North (AN).

respectively: Fig. 2). Saplings reached $50 \mathrm{~cm}$ in height within approximately $17 \mathrm{y}$ (AN) and $39 \mathrm{y}$ (AS).

We compared soil microsite characteristics of SP and TP. For the pooled stands, we found significantly higher litter, moss, shrub and juniper tree cover as well as deeper soils and lower rock cover for SP (Tab. II). For within-stand variation, soil depth, litter and rock cover were significantly higher in the surroundings of SP at AS, whereas litter, moss and shrub cover showed significantly higher levels for SP at AN. Significantly higher cone density on the ground was only recorded for SP at AN. At both stands, saplings occurred much nearer the nearest adult tree than expected from general tree density. Distance between TP and the nearest adult was the most important variable for distinguishing TP and SP, as indicated by the highest $z$-value of the statistical test (Tab. II). Consequently, juniper tree cover also increased significantly at TP.

The most important explanatory variables selected by classification tree models to explain presence of saplings appear in Figure 2. Distance to the nearest adult tree was the most influential predictor for sapling presence at both stands. Much higher probabilities of finding juniper saplings were observed for points closer than 2 and $3.28 \mathrm{~m}$ to the nearest adult tree for AS and AN respectively. Frequency distribution analysis of saplings confirmed that sapling density was highest 2 and $3 \mathrm{~m}$ away from the nearest adult tree for AS and AN respectively (Fig. 3). At site AS, 66\% of all saplings were found under the canopy of adult juniper trees, whereas only $22 \%$ of all saplings grow directly under the canopy of adults. Sapling density peaked at the crown edge at AN (Tab. I).

Classification tree analysis allowed us to evaluate the importance of explanatory variables in a hierarchical scheme (Fig. 2). The second most important variables for explaining sapling presence were different for the area outside and the area close to or under the canopy of adults at both stands. At AS, plots outside the canopy of nearest adult tree with soil depth $>4.3 \mathrm{~cm}$ and very low rock cover were more likely to contain juniper saplings. Plots under the canopy with a certain 
Table I. Differences between two juniper stands located on a south-facing (AS) and a north-facing slope (AN) with respect to microsite characteristics recorded in a circle of $1 \mathrm{~m}$ around the transect point (TP) and characteristics of nearest adult juniper trees and saplings. Nonparametric Kolmogorov-Smirnov test for independent groups was applied.

\begin{tabular}{|c|c|c|c|c|c|c|}
\hline & \multicolumn{2}{|c|}{$\mathrm{AS}$} & \multicolumn{2}{|c|}{ AN } & \multirow[b]{2}{*}{$Z$ value } & \multirow[b]{2}{*}{$p$} \\
\hline & Mean & SE & Mean & SE. & & \\
\hline \multicolumn{7}{|l|}{ Microsite characteristics at TP } \\
\hline Slope & 29.69 & 2.37 & 34.27 & 2.51 & 0.99 & 0.276 \\
\hline Soil depth & 6.07 & 0.64 & 9.59 & 0.92 & 1.48 & 0.026 \\
\hline Rock cover & 25.14 & 3.52 & 20.71 & 4.79 & 1.41 & 0.025 \\
\hline Stone cover & 13.58 & 1.72 & 6.82 & 0.87 & 1.58 & 0.013 \\
\hline Litter cover & 24.41 & 3.55 & 20.57 & 2.72 & 0.98 & 0.298 \\
\hline Bare soil & 21.43 & 2.27 & 26.43 & 3.22 & 0.75 & 0.635 \\
\hline Moss cover & 2.64 & 0.55 & 13.13 & 2.19 & 2.20 & 0.000 \\
\hline Herb cover & 20.09 & 2.27 & 14.74 & 1.81 & 1.12 & 0.166 \\
\hline Shrub cover & 14.00 & 2.93 & 12.91 & 3.10 & 0.60 & 0.868 \\
\hline Spiny shrub cover & 3.76 & 2.19 & 0.10 & 0.08 & 1.09 & 0.185 \\
\hline Juniper tree cover & 26.9 & 5.44 & 20.40 & 4.38 & 1.27 & 0.079 \\
\hline Erica arborea tree cover & - & - & 11.08 & 3.18 & - & - \\
\hline Cone density on the ground $\left(\mathrm{n}^{\circ} / \mathrm{m}^{2}\right)$ & 17.45 & 4.33 & 23.03 & 6.28 & 0.56 & 0.908 \\
\hline \multicolumn{7}{|l|}{ Juniper individuals characteristics } \\
\hline Cone production in crown $\left(\mathrm{n}^{\circ} / \mathrm{m}^{2}\right)$ & 66.49 & 17.40 & 148.78 & 35.69 & 1.40 & 0.039 \\
\hline Tree height $(\mathrm{cm})$ & 332.54 & 13.49 & 326.69 & 13.35 & 0.56 & 0.912 \\
\hline Tree DBH $(\mathrm{cm})$ & 28.13 & 2.71 & 25.12 & 2.46 & 0.83 & 0.492 \\
\hline Tree crown radius $(\mathrm{cm})$ & 225.26 & 10.28 & 202.65 & 10.09 & 1.05 & 0.220 \\
\hline Tree canopy closure $(\%)$ & 67.58 & 2.08 & 79.75 & 1.93 & 2.04 & $<0.001$ \\
\hline Tree vitality (\%) & 86.84 & 1.13 & 92.16 & 0.78 & 1.88 & 0.002 \\
\hline Sapling height $(\mathrm{cm})$ & 20.24 & 2.06 & 20.85 & 2.12 & 0.84 & 0.489 \\
\hline Sapling crown radius $(\mathrm{cm})$ & 12.99 & 1.64 & 16.60 & 2.37 & 0.64 & 0.805 \\
\hline Sapling vitaliy (\% green needles) & 59.40 & 2.93 & 67.73 & 2.75 & 1.57 & 0.015 \\
\hline Sapling density ( $\left.\mathrm{n}^{\circ} / \mathrm{ha}\right)$ & 226.75 & 42.95 & 655.15 & 128.36 & 1.53 & 0.018 \\
\hline
\end{tabular}

Table II. Differences between transect point (TP, absence of sapling) and sapling point (SP, presence of sapling) of two juniper habitats located on a south-facing (AS) and a north-facing slope (AN) with respect to microsite characteristics recorded in a circle of $1 \mathrm{~m}$ radius around TP/SP, cone density on the ground and distance to nearest adult juniper tree. Non-parametric Wilcoxon test for related pairs of data was applied.

\begin{tabular}{|c|c|c|c|c|c|c|}
\hline \multirow[b]{2}{*}{ Variable } & \multicolumn{2}{|c|}{ AS } & \multicolumn{2}{|c|}{ AN } & \multicolumn{2}{|c|}{ Pooled } \\
\hline & $\bar{Z}$ & $p$ & $Z$ & $p$ & $Z$ & $p$ \\
\hline Slope & -0.70 & 0.485 & -0.09 & 0.928 & -0.43 & 0.667 \\
\hline Soil depth & -4.02 & $<0.001$ & -0.25 & 0.806 & -3.13 & 0.002 \\
\hline Rock cover & -2.43 & 0.015 & -0.31 & 0.756 & -2.18 & 0.029 \\
\hline Stone cover & -0.46 & 0.643 & -1.26 & 0.208 & $-0,43$ & 0.663 \\
\hline Litter cover & -1.96 & 0.049 & -3.00 & 0.003 & -3.35 & $<0.001$ \\
\hline Bare soil & -1.24 & 0.216 & -1.45 & 0.146 & -0.13 & 0.895 \\
\hline Moss cover & -0.61 & 0.544 & -2.19 & 0.028 & -2.21 & 0.027 \\
\hline Herb cover & -0.97 & 0.332 & -1.95 & 0.051 & -0.47 & 0.637 \\
\hline Shrub cover & -1.79 & 0.073 & -2.59 & 0.009 & -2.99 & 0.003 \\
\hline Spiny shrub cover & -1.92 & 0.055 & -0.68 & 0.498 & -1.35 & 0.177 \\
\hline Juniper tree cover & -2.95 & 0.003 & -2.39 & 0.017 & -3.67 & $<0.001$ \\
\hline Erica arborea tree cover & - & - & -0.88 & 0.378 & - & - \\
\hline Distance to nearest adult tree & -4.18 & $<0.001$ & -3.67 & $<0.001$ & -5.53 & $<0.001$ \\
\hline Cone density on the ground & -0.14 & 0.889 & -2.58 & 0.010 & -1.99 & 0.047 \\
\hline
\end{tabular}



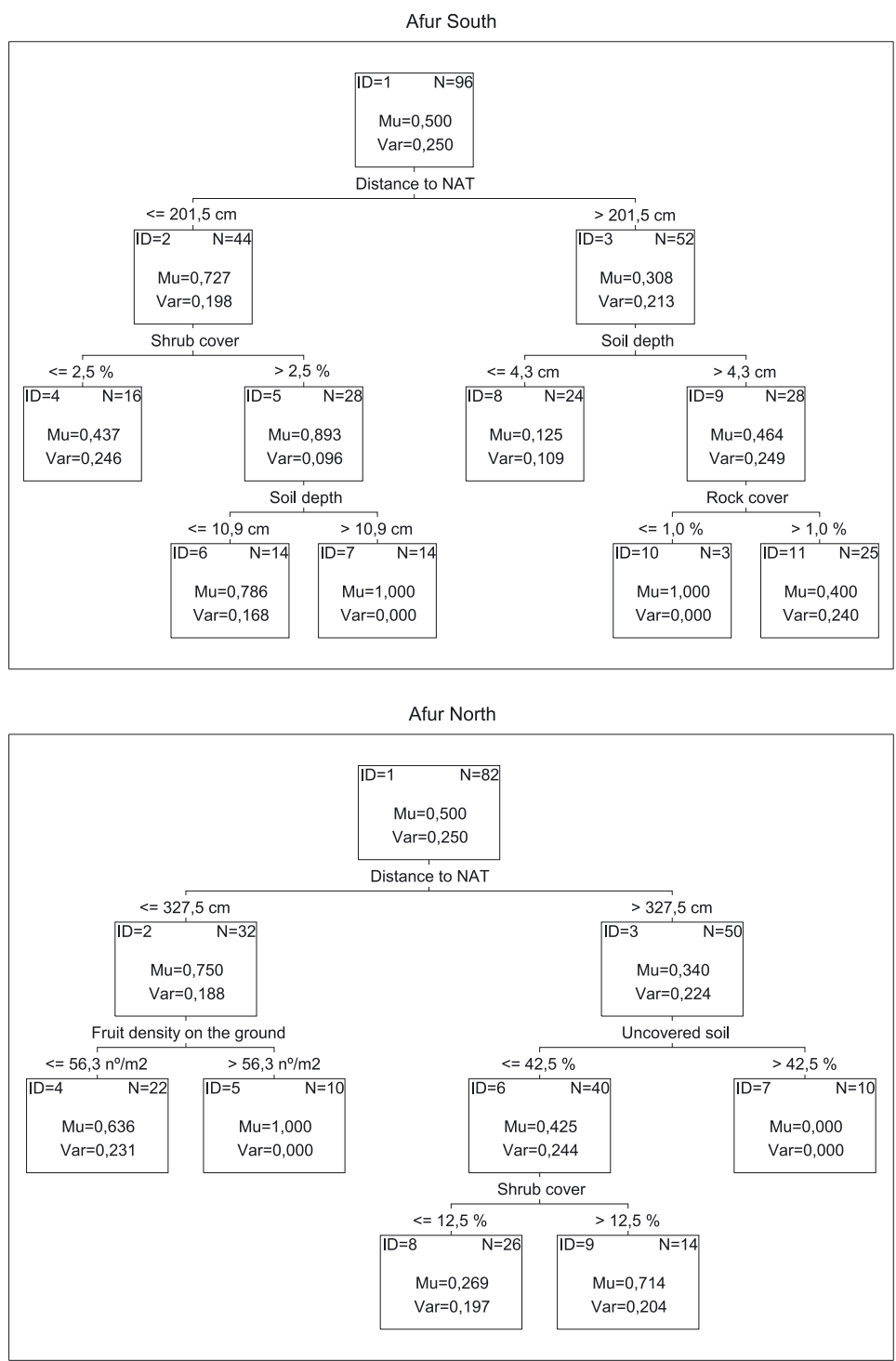

Figure 3. Classification trees for sites Afur South and Afur North, including eight explanatory variables and sapling occurrence as response variable. $(\mathrm{NAT}=$ nearest adult tree, $\mathrm{Mu}=$ node mean, $\mathrm{Var}=$ node variance, $N=$ the number of observations in that particular group, ID $=$ node number.) Full classification tree are shown, stopped by the minimum size of group set to be 20 .

shrub cover $(>2.5 \%)$ and deeper soils $(>11 \mathrm{~cm})$ had more saplings. At the north-facing stand AN and outside the direct influence of the canopy of adults (distance to nearest adult tree $>3.28 \mathrm{~m}$ ), saplings established preferentially within plots with low levels of uncovered soil $(<42.5 \%)$ and with at least $12.5 \%$ shrub cover. Near or under the canopy of adults, high cone density on the ground and higher shrub cover $(>31 \%)$ positively influenced sapling presence.

GLM results confirmed the importance of distance to nearest adult tree, soil depth and shrub cover for sapling establishment at AS. Distance to the nearest adult tree, cone density on the ground, uncovered soil and shrub cover were selected by AIC for AN (Tab. III). GLMs did not find any biotic and abiotic variable that would explain variation in sapling vitality.

\section{DISCUSSION}

We have shown that most of the selected soil characteristics in Canarian juniper woodlands varied substantially over different spatial scales. These scales ranged from a fine scale (i.e., around transect and sapling points) to intermediate (distance to nearest adult juniper trees) and larger scales (two juniper stands situated on opposite slopes). Microsite conditions around juniper saplings differed significantly compared to general site conditions recorded around the systematically selected transect points. These findings suggest spatial association of juniper recruitment with relatively low rock cover, deep soils, high litter and vegetation cover (juniper tree or shrub cover), as well as low levels of uncovered soil. 
Table III. Results of generalized linear models (GLMs), showing the best set of explanatory variables explaining sapling presence/absence as response variable for the south-facing juniper habitat (AS), the north-facing habitat (AN) and both habitats pooled, using AIC (Akaike information criterion) best set selection and Binominal distribution with logistic link function. Models explained 20.1\%, 26.1\% and $18.8 \%$, respectively, of the total deviance.

\begin{tabular}{|c|c|c|c|c|c|c|}
\hline \multirow[b]{2}{*}{ Afur South } & \multicolumn{4}{|c|}{ Parameter estimates } & \multicolumn{2}{|c|}{ Model building results } \\
\hline & Estimate & SE & Wald's $\chi^{2}$ & $p$ & AIC & $p$ \\
\hline Distance to nearest adult tree & 0.004 & 0.002 & 6.663 & 0.009 & 115.16 & $<0.0001$ \\
\hline Soil depth & -0.123 & 0.053 & 5.510 & 0.019 & & \\
\hline Shrub cover & -0.027 & 0.013 & 4.600 & 0.032 & & \\
\hline \multicolumn{7}{|l|}{ Afur North } \\
\hline Distance to NAT & 0.003 & 0.001 & 7.112 & 0.007 & 95.76 & $<0.0001$ \\
\hline Cone density on the ground & -0.008 & 0.004 & 4.497 & 0.034 & & \\
\hline Shrub cover & -0.029 & 0.014 & 4.440 & 0.035 & & \\
\hline Bare soil & 0.033 & 0.016 & 4.069 & 0.044 & & \\
\hline \multicolumn{7}{|l|}{ Pooled data } \\
\hline Distance to nearest adult tree & 0.003 & 0.001 & 16.338 & $<0.001$ & 213.50 & $<0.0001$ \\
\hline Shrub cover & -0.024 & 0.009 & 7.388 & 0.007 & & \\
\hline Cone density on the ground & -0.006 & 0.003 & 4.450 & 0.035 & & \\
\hline Soil depth & -0.061 & 0.031 & 3.750 & 0.053 & & \\
\hline
\end{tabular}
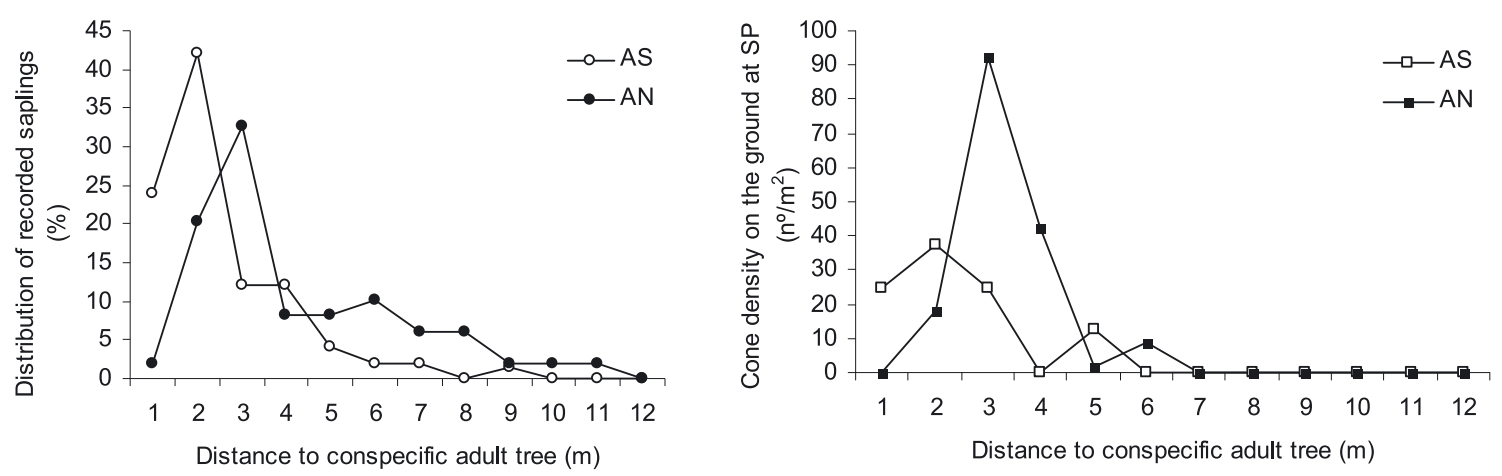

Figure 4. Distribution of cones on the ground and relative abundance of saplings (frequency) in relation to distance to nearest adult for sites Afur South (AS) and Afur North (AN). Cone density was measured at each sapling point (SP) in four $20 \times 20$ cm quadrates, located symmetrically around the individual/point within a circle of $1 \mathrm{~m}$. Distribution of saplings are represented as percentage of saplings per distance classes.

We confirmed that the combination of soil microsite characteristics having a positive influence on presence of juniper saplings varied with distance to the nearest adult juniper tree and between stands, as confirmed by the classification tree models. Some factors, such as litter cover and canopy cover and ameliorating micro-environmental conditions through shading, are strongly related to the presence of adult trees. Small-scale soil characteristics, such as soil depth or rock cover, vary on a smaller spatial scale (Herrera, 2002; Smit et al., 2005) and can have positive or negative effects on recruitment independently of the presence of adults. Therefore, the level of spatial heterogeneity over which different abiotic and biotic factors operate may be important for studying regeneration in this semi-arid woodland.

Montesinos et al. (2007) showed that all life stages in Juniperus thurifera recruitment are favoured underneath adults, where microhabitats offer more favourable soil and micro-climatic conditions compared to open space. Similarly, favourable conditions for recruitment for the Canarian juniper seem strongly related to the area under or at the edge of the canopy of parental trees, as indicated by all statistical tests applied and by frequency analyses of saplings. This spatial association is probably related to a nurse plant effect by mother plants, as reported for other Mediterranean ecosystems (Gómez-Aparicio et al., 2005; Padilla and Pugnaire, 2006). Such association also relates to seed availability, a variable that had its highest values at the canopy edge of adults. Distance between recruits and conspecific adults is important for explaining spatial patterns of recruitment in Mediterranean juniper and oak species (Maltez-Mouro et al., 2007; 2009; Milios et al., 2007. Interestingly, juniper saplings were not associated with the canopies of the other tree species (Erica arborea) at AN, indicating that regeneration is, in fact, strongly related to mother trees and that secondary dispersal to similar microhabitats is less frequent.

Litter cover, here strongly related to microhabitat under or near the adult canopy, can favour emergence of seedlings through enhanced imbibition of seeds and retained moisture necessary for germination (Facelli et al., 1999; Matthes and Douglas, 2006; Maltez-Mouro et al., 2007).

Shrub cover had an overall positive effect on presence of saplings, independently of distance to nearest adult. The most 
common shrub species growing near juniper saplings were Globularia salicina at AS and Artemisia thuscula and Rubia fruticosa at AN. The facilitative effect of shrubs on tree recruitment has been related to microclimatic amelioration through shading (Gómez et al., 2005a; Maestre et al., 2003), resulting in reduced drought stress that can be especially important in the first years of seedling establishment in semi-arid environments (Garcia, 2001; Montesinos et al., 2007; Owens et al., 1995; Weltzin and McPherson, 1999). On the other hand, facilitation by shrubs can also be the result of protection from herbivory (Olano et al., 2008; Rozas et al., 2008). Although not directly measured in this study, we suggest that the observed facilitative effect (nurse plant effect) can be attributed to amelioration of limiting physical stress and not to protection from herbivory, since browsing pressure was low during the last decades (Mata et al., 2006) and spiny shrubs did not seem to favour tree recruitment (Smit et al., 2005).

Because they serve as perches and as seed traps for secondary dispersal, shrubs can also play an important role in shaping the spatial distribution of recruits of fleshy-fruited tree species (Kollmann, 2000). In view of the concordance between spatial distributions of cones on the ground and saplings, we suggest that this is a minor influence on regeneration of $\mathrm{Ca}$ narian juniper, although frugivorous birds, able to disperse the cones and seeds of this species, are present in the stands studied. Since the Canarian raven, considered the principal disperser for the studied species, has almost become extinct on Tenerife, endemic lizards (genus Gallotia) are now considered the main seed dispersers (Fernández-Palacios et al., 2008). These lizards are common all over the study area. Mammals (i.e. domestic cats, Felis catus L.) occasionally disperse viable seeds of the Canarian juniper (Nogales et al., 1996). Rabbits (Oryctolagus cuniculus L.) are known to disperse as well as to destroy seeds of Juniperus phoenicea L. ssp. turbinata (Guss.) (Muñoz, 1993). With only lizards remaining as secondary dispersal agents for the Canarian juniper, we might expect less long-distance dispersal and fewer new colonisations in regions where this species has been eliminated. However, we lack detailed studies of these recruitment processes. Future investigations should focus on effects of seed dispersal, on predation by birds, mammals and lizards, and on their possible preferences for certain microsites.

The north-facing juniper stand showed better soil conditions. These soil conditions can be related to higher waterholding capacity, lower levels of hydric stress, and, consequently, higher overall productivity. Rocky and shallow soils usually have lower amounts of soil moisture. These lower moisture levels negatively affect seedling establishment and sapling growth (Owens et al., 1995). This effect would explain our finding of negative effects of soil depth and rock cover on sapling establishment at AS. In general, slope orientation had a strong effect on sapling vitality and growth rate as well as on adult vitality and crown cone production. Saplings are much more abundant at the north-facing site, where they grow much faster and exhibit higher vitality compared to their performance at the south-facing site. These results are probably the consequence of overall higher productivity. That differences in environmental stress related to topography can affect facilitation and regeneration patterns has been reported for semi-arid juniper woodlands (Johnson and Millar, 2006), as well as for tree regeneration along altitudinal gradients in Mediterranean ecosystems (Gómez-Aparicio et al., 2004). However, since the north-facing stand suffered more from selective tree cutting in the past and since its present adult tree density is lower than would be expected based on site productivity, we cannot exclude a possible effect of release from intra-specific competition on sapling growth and juniper regeneration.

That herbivory can explain the observed differences in sapling growth rates between stands is not very likely. Browsing pressure by goats has been reported to be very low and of the same intensity for both stands studied (Mata et al., 2006). Nevertheless, young individuals and adult trees (height $>50 \mathrm{~cm}$ ) might have suffered growth suppression due to intense browsing in the past, but cessation or reduction of browsing generally occurred about $40 \mathrm{y}$ ago on the Canary Islands. Therefore, spatial distribution of saplings in this study (all individuals are younger than $40 \mathrm{y}$ ) ought not to be strongly influenced by this factor. Browsing is considered important for shaping the structure of other juniper woodlands (Olano et al., 2008), but browsing is less important for recruitment of other Mediterranean tree species (Gómez-Aparicio et al., 2008).

\section{CONCLUSIONS}

Regeneration of the Canarian juniper seems to be related to proximity of conspecific adults. Nearness of conspecific adults implies favourable micro-environmental conditions and high local seed availability. These factors favour seedling establishment. In addition to and independently of the presence of adults, increased soil depth, lower level of rockiness and presence of shrubs can influence tree recruitment positively. Slope orientation, related to environmental stress, also influences spatial distribution of saplings and regeneration processes of this juniper species. Effects of browsing pressure on tree regeneration were not observed in this study. Browsing might still influence regeneration processes in Canarian juniper woodlands where herbivory by goats or sheep is important, e.g., on the island of El Hierro (Salvà-Catarineu and Romo-Díez, 2008).

The effect of nurse shrubs on seedling establishment and survival of tree species can be used for restoration management procedures, as highlighted recently (Padilla and Pugnaire, 2006). In this context, our results are applicable to future restoration programmes in Canarian juniper woodlands and other remaining thermophilous forests.

Acknowledgements: In consideration of the massive loss of juniper woodlands on Tenerife, the local authorities (Cabildo Insular de Tenerife) started a project, financed by the European Community (LIFE04/NAT/ES/000064), to restore a Juniperus turbinata woodland at Teno mountains (NW corner of Tenerife). This study is a result of this project. We wish to thank Sonja Schaffner and Pascal Meuwly for their invaluable help during field work. Two anonymous referees revised the manuscript and supported valuables comments. 


\section{REFERENCES}

Chambers J.C., 2001. Pinus monophylla establishment in an expanding Pinus-Juniperus woodland: Environmental conditions, facilitation and interacting factors. J. Veg. Sci. 12: 27-40.

Crawley M.J., 1993. GLIM for Ecologists. In: Lawton J.H. and Likens G.E., (Eds.), Methods in Ecology, Series 15, Blackwell Scientific Publications, Oxford, pp. 1-379.

Dobson A.J., 1990. An Introduction to Generalized Linear Models, Chapman and Hall, London.

Facelli J.M., Williams R., Fricker S., and Ladd B., 1999. Establishment and growth of seedlings of Eucalyptus obliqua: Interactive effects of litter, water, and pathogens. Aust. J. Ecol. 24: 484-494.

Fernández-Palacios J.M., Otto R., Delgado J.D., Arévalo J.R., Morici C., González-Artiles F., Naranjo A., and Barone, R. 2008. Los bosques termófilos de Canarias. Cabildo Insular de Tenerife/ LIFE Natura, $192 \mathrm{p}$.

García D., 2001. Effects of seed dispersal on Juniperus communis recruitment on a Mediterranean mountain. J. Veg. Sci. 12: 839-848.

García D. and Houle G., 2005. Fine-scale patterns of recruitment in red oak (Quercus rubra): What matters most, abiotic or biotic factors? Ecoscience 12: 223-235.

Gómez-Aparicio L., 2008. Spatial patterns of recruitment in Mediterranean plant species: linking the fate of seeds, seedlings and saplings in heterogeneous landscapes at different scales. J. Ecol. 96: $1128-1140$.

Gómez-Aparicio L., Zamora R., Gómez J.M., Hódar J.A., Castro J., and Baraza E., 2004. Applying plant facilitation to forest restoration. A meta-analysis of the use of shrubs as nurse plants. Ecol. Appl. 14: $1128-1138$.

Gómez-Aparicio L., Gómez J.M., Zamora R., and Boettinger J.L., 2005. Canopy vs. soil effects of shrubs facilitating tree seedlings in Mediterranean montane ecosystems. J. Veg. Sci. 16: 191-198.

Gómez-Aparicio L., Zamora R., Castro J., and Hodar J.A., 2008. Facilitation of tree saplings by nurse plants: Microhabitat amelioration or protection against herbivores? J. Veg. Sci. 19: 161-172.

Herrera C.M., 2002. Topsoil properties and seedling recruitment in Lavandula latifolia: stage-dependence and spatial decoupling of influential parameters. Oikos 97: 260-270.

Izquierdo I., Martín J.L., Zurita N., and Arechavaleta M., 2004. Lista de especies silvestres de Canarias (hongos, plantas y animales terrestres). Consejería de Medio Ambiente y Ordenación Territorial, Gobierno de Canarias.

Johnson D.D. and Millar R.F., 2006. Structure and development of expanding western juniper woodlands as influenced by two topographic variables. For. Ecol. Manage. 229: 7-15.

Kollmann J., 2000. Dispersal of fleshy-coned species: A matter of spatial scale? Perspect. Plant Ecol. Evol. Syst. 3: 29-51.

Lechowicz M.J. and Bell G., 1991. The ecology and genetics of fitness in forest plants. II. Microspatial heterogeneity of the edaphic environment. J. Ecol. 79: 687-696.

Maestre F.T., Bautista S., and Cortina J., 2003. Positive, negative, and net effects in grass-shrub interactions in Mediterranean semiarid grasslands. Ecology 84: 3186-3197.

Maltez-Mouro S., García L.V., Marañón T., and Freitas H., 2007. Recruitment patterns in a Mediterranean oak forest: a case study showing the importance of the spatial component. For. Sci. 53: $645-652$

Maltez-Mouro S., García L.V., and Freitas H., 2009. Influence of forest structure and environmental variables on recruit survival and performance of two Mediterranean tree species (Quercus faginea $\mathrm{L}$. and Q. suber Lam.). Eur. J. For. Sci. 128: 27-36.

Mata J., Bermejo L.A., de Nascimento L., and Salvador Hernández L., 2006. Informe final del plan de seguimiento y control del pastoreo. Parque Rural de Anaga, 2001-2005. Consejería de Medio Ambiente, Gobierno de Canarias, Universidad de La Laguna.
Matthes U. and Douglas W.L., 2006. Microsite and climatic controls of tree population dynamics: an 18-year study on cliffs. J. Ecol. 94: 402-414.

Milios E., Pipinis E., Petrou P., Akritidou S., Smiris P., and Aslanidou M., 2007. Structure and regeneration patterns of the Juniperus excelsa Bieb. stands in the central part of the Nestos valley in the northeast of Greece, in the context of anthropogenic disturbances and nurse plant facilitation. Ecol. Res. 22: 713-723.

Montesinos D., Verdú M., and García-Fayos P., 2007. Moms are better nurses than dads: gender biased self-facilitation in a dioecious Juniperus tree. J. Veg. Sci. 18: 271-280.

Mueller-Dombois D. and Ellenberg H., 1974. Aims and Methods of Vegetation Ecology. John Wiley \& Sons, Inc., New York, Chichester, Brisbane und Toronto.

Muñoz J.C., 1993. Consumo de gálbulos de Sabina (Juniperus phoenicea ssp. turbinata Guss, 1981) y dispersión de semillas por el Conejo (Oryctolagus cuniculus L.) en el Parque Nacional de Doñana. Doñana, Acta Vertebrata 20: 49-58.

Nogales M., Medina F.M., and Valido A., 1996. Indirect seed dispersal by the feral cats Felis catus in island ecosystems (Canary Islands). Ecography 19: 3-6.

Olano J.M., Rozas V., Bartolomé D., and Sanz D., 2008. Effects of changes in traditional management on height and radial growth patterns in a Juniperus thurifera L. woodland. For. Ecol. Manage. 255: 506-512.

Otto R., Krüsi B.O., Schaffner S., Meuwly P., Delgado J.D., Arévalo J.R., and Fernández-Palacios J.M., 2006. Ecología, estructura y dinámica de las poblaciones de la sabina canaria (Juniperus turbinata ssp. canariensis) en Tenerife y La Gomera. In: García González M.D. et al. (Eds.), Actas del III coloquio internacional sobre los sabinares y enebrales (Género Juniperus): Ecología y gestión forestal sostenible en Soria. Junta de Castilla y León y comunidad de Madrid, Tomo I: 151-160.

Owens M.K., Wallace R.B., and Archer S.R., 1995. Landscape and microsite influences on shrub recruitment in a disturbed semi-arid Quercus-Juniperus woodland. Oikos 74: 493-502.

Padilla F.M. and Pugnaire F.I., 2006. The role of nurse plants in the restoration of degraded environments. Front. Ecol. Environ. 4: 196-202.

Rey P.J. and Alcántara J.M., 2000. Recruitment dynamics of a fleshyfruited plant (Olea europaea): connecting patterns of seed dispersal to seedling establishment. J. Ecol. 88: 622-633.

Rozas V., Olano J.M., DeSoto L., and Bartolomé D., 2008. Large-scale structural variation and long-term growth dynamics of Juniperus thurifera trees in a managed woodland in Soria, central Spain. Ann. For. Sci. 65: 809 .

Salvà-Catarineu M. and Romo-Díez A., 2008. Uso de TIG para la conservación del sabinar de Juniperus turbinata subsp. canariensis en la isla de El Hierro. In: Hernández L. and Parreño J.M. (Eds.), Tecnologías de la Información Geográfica para el Desarrollo Territorial. Servicio de Publicaciones y Difusión Científica de la ULPGC, Las Palmas de Gran Canaria, pp. 766-776.

Smit C., Béguin D., Buttler A., and Müller-Schärer H., 2005. Safe sites for tree regeneration in wooded pastures: A case of associational resistance? J. Veg. Sci. 16: 209-214.

Smit C., Diaz M., and Jansen P., 2009. Establishment limitation of holm oak (Quercus ilex subsp. ballota (Desf.) Samp.) in a Mediterranean savanna - forest ecosystem. Ann. For. Sci. 66: 511.

Sokal R.R. and Rohlf F.J., 2005. Biometry. The principles and practice of statistics in biological research. 4th ed., Freeman and Co., New York.

Weltzin J.F. and McPherson G.R., 1999. Facilitation of conspecific seedling recruitment and shifts in temperate savanna ecotones. Ecol. Monogr. 69: 513-534.

Zuur A.F., Ieno E.N., and Smith G.M., 2007. Analysing Ecological Data. Springer, USA. 